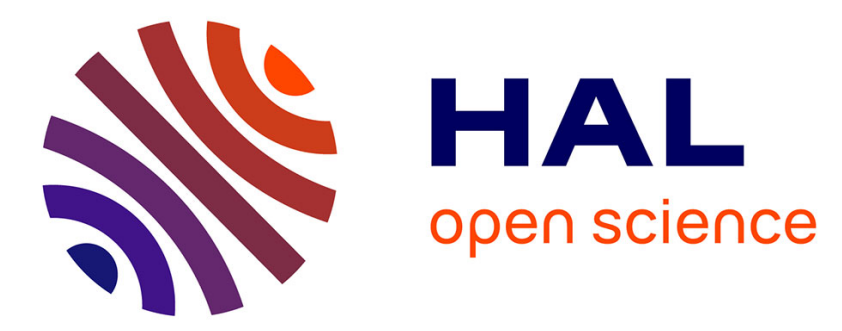

\title{
Assessment of illness representations in mental disorders: A mini review
}

Priscillia Averous, Elodie Charbonnier, Lionel Dany

\section{To cite this version:}

Priscillia Averous, Elodie Charbonnier, Lionel Dany. Assessment of illness representations in mental disorders: A mini review. L'Encéphale, 2021, 47 (2), pp.137-142. 10.1016/j.encep.2020.09.011 . hal03141150

\author{
HAL Id: hal-03141150 \\ https://hal.science/hal-03141150
}

Submitted on 27 May 2021

HAL is a multi-disciplinary open access archive for the deposit and dissemination of scientific research documents, whether they are published or not. The documents may come from teaching and research institutions in France or abroad, or from public or private research centers.
L'archive ouverte pluridisciplinaire HAL, est destinée au dépôt et à la diffusion de documents scientifiques de niveau recherche, publiés ou non, émanant des établissements d'enseignement et de recherche français ou étrangers, des laboratoires publics ou privés.

\section{(ㅇ)(1) $\$$}

Distributed under a Creative Commons Attribution - NonCommercial - NoDerivatives| 4.0 


\title{
Review of the literature
}

\section{Assessment of illness representations in mental disorders: A mini
review}

\author{
Évaluation des représentations dans les troubles psychiques : une mini revue \\ P. Averous a,b, , E. Charbonnier ${ }^{\mathrm{b}}$, L. Dany ${ }^{\mathrm{a}, \mathrm{c}}$ \\ a Aix Marseille Univ, Aix-en-Provence, France \\ ${ }^{\mathrm{b}}$ UNIV. NIMES, APSY-V. Nîmes cedex 1, France \\ 'APHM, Timone, Service d'Oncologie Médicale, Marseille, France
}

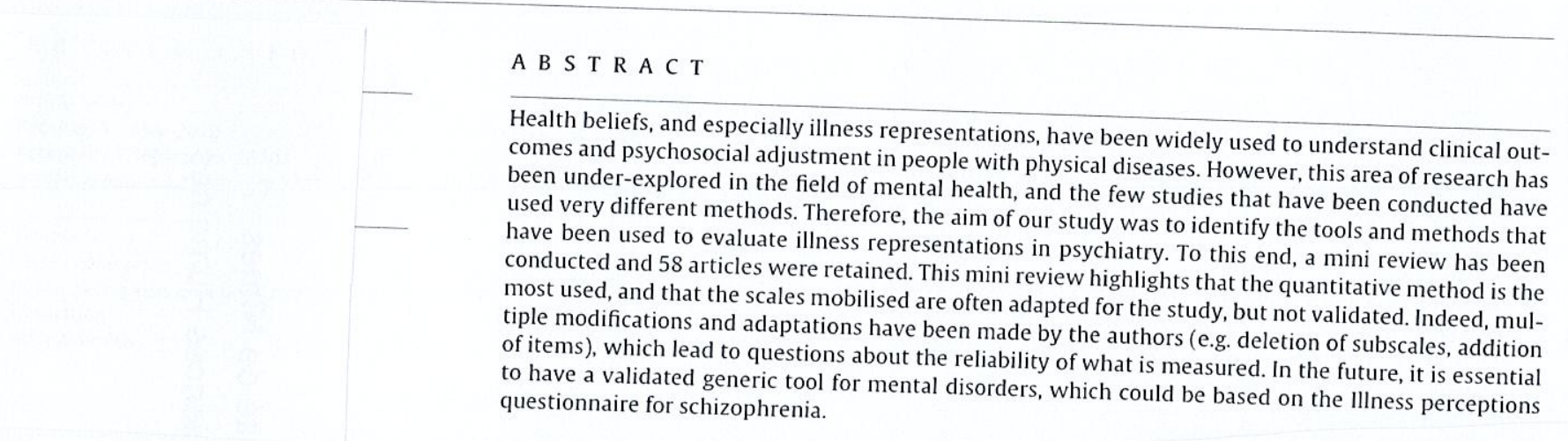

Mots clés:

Perception de la maladie

Questionnaire des représentations de la

maladie

Évaluation

Santé mentale

\section{R É S U M É}

Les croyances en matière de santé, et en particulier, les représentations de la maladie, ont été largement utilisées pour comprendre les issues cliniques et l'adaptation psychosociale des personnes présentant une maladie physique. Cependant, ce domaine de recherche a été sous-exploré en psychiatrie. Pourde nombreux troubles mentaux les représons semblent prometteurs. En effet, ils soulignent que dans santé (comme par exemple, l'adhérence au tations de la maladie sont corrélées aux comportements de psychosociale (comme par exemple, la qualité de vie)) l'engagement dans le soin), ainsi qu'à l'adaptation tions de la maladie en santé mentale se sont con vie). Cependant, les études évaluant les représentavalidés pour les personnes présentant un troufrontées à l'absence d'outils spécifiquement conçus et méthodologiques au sein de la littérature. Or, pour disposer d'une, conduisant à d'importantes différences de la maladie en santé mentale, il nous sem, pour disposer d'une connaissance fiable des représentations tions sont mesurées. Ainsi, l'objectif semble indispensable de comprendre comment ces représentaont été utilisés pour évaluer les représentatie mini revue est d'identifier les outils et les méthodes qui bles mentaux. À partir des bases de dentions de la maladie des personnes atteintes de différents trouPubMed, nous avons retenu 58 articles scientifineniques PsycINFO, PsycARTICLES, Web of Science et personnes présentant un trouble psychiatrique. sont ceux qui ont été validés auprès de personnes résultats indiquent que les outils les plus utilisés perception questionnaire revised et le Briefillness perception un trouble physique, plus précisément Illness mentaux, la plupart des études ont procédé às perception questionnaire. Afin de les adapter aux troubles exemple, des sous-échelles ont été modifiées multiples adaptations et modifications de ces outils (par

\footnotetext{
* Corresponding author at: Aix-Marseille université, Maison de la recherche SCHUMAN, 29, avenue R.-Schuman, 13628 Aix-en-Provence, France
E-mail address: priscillia.averous@gmail.com (P. Averous).
} 
reformulées). Il est également important de relever que même les outils qui ont été validés auprès de personnes présentant un trouble psychiatrique ont également l'objet de modifications selon les études, c'est notamment le cas de l'Illness perceptions questionnaire for schizophrenia. Ces multiples modifications et adaptations peuvent conduire à s'interroger sur la fiabilité de ce qui est mesuré, et donc des connaissances qui en sont issues. Si l'étude des représentations de la maladie en psychiatrie semble tout à fait essentielle, il est indispensable que les recherches futures adoptent une méthodologie plus rigoureuse et homogène. Pour ce faire, l'utilisation d'un questionnaire transdiagnostique s'inspirant de l'Illness perceptions questionnaire for schizophrenia apparaît être tout indiqué.

\section{Introduction}

Mental disorders are often characterised by low adherence and poor health outcomes [1-5]. Therefore, it is essential to understand the processes underlying health behaviours of people with a mental disorder. Several models (e.g. Health Belief Mode [6]; Self-Regulation Model [7]; Theory of Planned Behaviour [8], Capability-Opportunity-Motivation-Behaviour System [9]) have shown that beliefs and attitudes about illness play a central role in health behaviours. More specifically, illness representations, i.e. a set of beliefs about the nature of an illness, may influence an individual's coping with illness, psychosocial adjustment and emotional responses. While these associations have been widely investigated for physical illness (for meta-analysis, see $[10,11]$ ). studies in the field of mental health are more rare. They point out that, across a wide range of mental disorders, illness perceptions are associated with health behaviour (e.g. adherence, preference for treatment) and psychosocial adjustment (e.g. quality of life) (for a review, see [12-14]). Thus, despite the small number of studies on the subject, illness representations seem to provide an interesting heuristic framework for understanding the adaptation to illness of people with a mental disorder.

Initially, Weinman, Petrie, Moss-Morris \& Horne [15] created the illness perception questionnaire (IPQ) to measure illness representations for various physical illnesses. The IPQ evaluates five dimensions of illness representations: causes (factors believed to be responsible for the illness or condition), identity (overall comprehensibility of the illness), timeline (considering whether the illness is chronic), consequences (assessing its impact on life, including physical, emotional, social and economic outcomes) and cure/control (belief that the illness is cured by treatment or can be controlled by the patient's actions). Thereafter, a revised version was proposed, the Illness perception questionnaire revised (IPQ$R$; [16]). The IPQ-R evaluated additional dimensions: emotional representation (emotional impact or emotional response to the illness), coherence (how people understood their illness), chronicity and cyclicity (previously combined in timeline), personal control and treatment control (previously combined in cure/control). More recently, a brief version was created, the Brief illness perception questionnaire (B-IPQ [17]), that measures in nine items, all illness representations, except cyclicity, is today a popular tool [18]. All of these tools have been validated with people with various physical illnesses. As a result, the few studies conducted in the field of mental health have been confronted with the lack of tools specifically validated for mental disorders. Yet, in order to have reliable knowledge about the illness representations for mental disorders, it is necessary to understand how these representations are captured. For these reasons, the aim of the current review is to identify the tools and methods that have been used to evaluate illness representations for people with mental disorder.

\section{Method}

To identify articles evaluating illness representations in mental disorders, we used the following keywords: self-regulation model OR illness perception* OR illness representation* OR AND mental disorder* OR mental health. We conducted electronic searches on PsycINFO, PsycARTICLES, Web of Science and PubMed to identify both qualitative and quantitative studies published between 1980 and June 2017.

The following inclusion criteria were applied:

- published empirical study (quantitative or qualitative) or research report examining illness representations of people with mental health problems:

- article written in English or French and published in a peerreviewed journal.

Articles were excluded if they:

- were published as a book chapter;

- were not written in English or French;

- explored illness representations for physical diseases;

- explored illness representations from the perspective of healthy people.

Data were extracted by one reviewer. All titles and abstracts yielded in the initial search were screened by one reviewer to identify articles for full-text retrieval and checked by two reviewers. All full-text articles were independently screened by the three. Data were extracted by one reviewer and checked for accuracy by another reviewer. The extracted data were:

- author;

- year;

- mental disorder studied;

- study design and methodology;

- measures used (See E-component).

The literature searches produced 6384 results, but 2271 papers were excluded because they were duplicates. The screening of titles and abstracts led to a further 2645 being excluded, either because of the type of article (e.g., book, editorial, language) or the nature of the population (physical illness, healthy individuals), or because the articles were not accessible. Full-text screening resulted in the exclusion of a further 1414 articles, because they did not address illness perceptions or psychiatric diagnoses, were reviews, theoretical papers or case studies. In addition, four papers [19-22], published after June 2017, were added, as they were relevant to this review. At the end of this screening process, a total of 58 studies remained. Fig. 1 shows a flow diagram for the study selection process. 


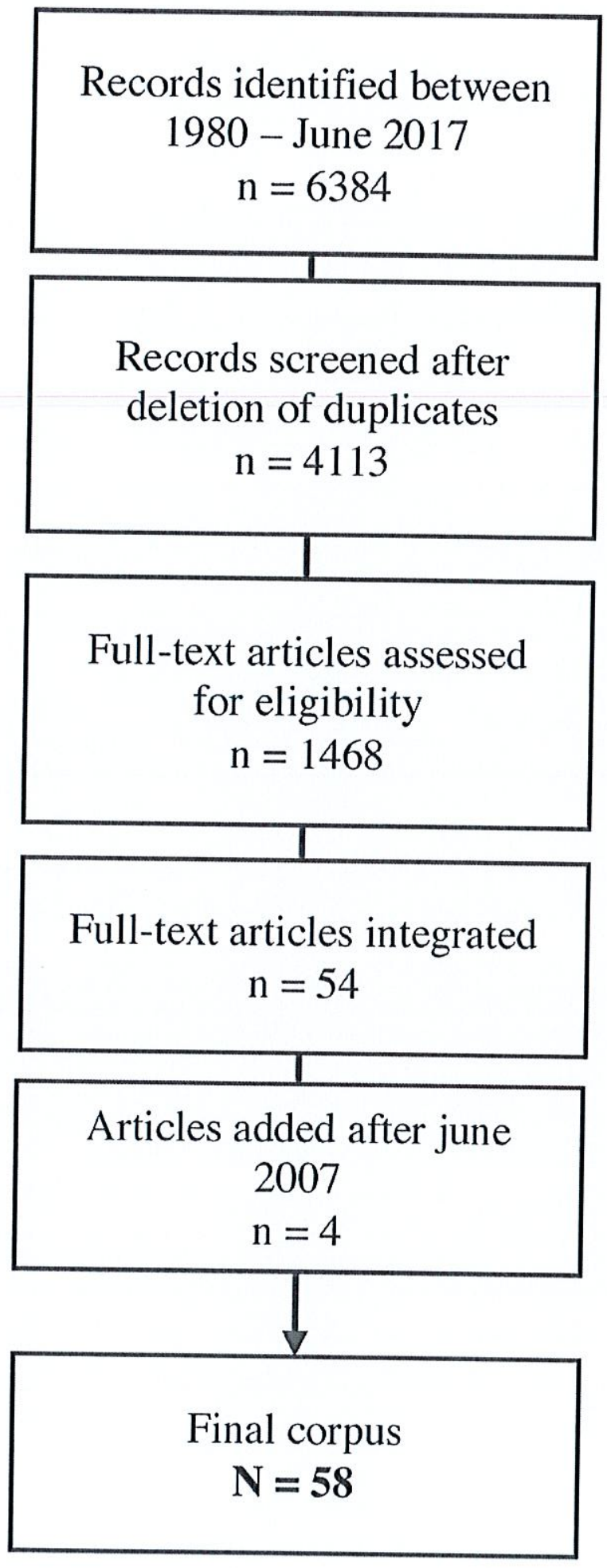

Fig. 1. Flow diagram for the study selection process.

\section{Results}

Our review showed that in order to evaluate illness representations for people with mental disorders, the quantitative method is mainly used. The main questionnaires used are those that have been validated for physical diseases (IPQ-R and B-IPQ). To a lesser extent, questionnaires have been specifically validated for mental disorders (Modified-Illness representations questionnaire: M-IPQ; Illness perceptions questionnaires for schizophrenia: IPQ-S). Finally, two studies used qualitative approach. The Table 1 describes the different tools used.

\subsection{Illness perception questionnaire revised (IPQ-R)}

The IPQ-R was the most used to assess illness representations for mental disorders (Table 2). It was used for people with mixed mental disorders $(n=7 ;[23-29])$, unipolar disorders $(n=5$; [30-34]), eating disorders $(n=3$; [35-37]), mood disorders $(n=2$; $[38,39])$, bipolar disorder $(n=1 ;[40])$, or affective and disruptive disorders $(n=1 ;[41])$. In order to adapt its use to mental disorders, the authors have made several adaptations and modifications, which are summarised in Table 3. More precisely, seven studies [26-29,31,33,41] replaced the term "illness" in the scale instructions with "depression" [31,33], "mental health problems" [27], "mental illness" [28], "problems" [29] or "behavioural/emotional problems" [26,41]. In addition, seven studies [27-33] changed the subscales of the IPQ-R. The cause subscale is the one that has been modified the most, either by adding items [30], by replacing it with other tools (e.g. Faller's self-report on perceived causes [27], the causal belief questionnaire [29]), or by creating new categories (e.g. psychological attributions, physical attributions, and social attributions [33], or family-related stress, social stress, alcohol and other drugs [28]). In three studies, the identity subscale was replaced by items of the Symptom Checklist-90 [29], the Brief Symptom Inventory [28], or the Patient Health Questionnaire-9 [31]. In one study [32], the cure/control has been divided into three categories: external control, personal control, and treatment control. The same study also divided the timeline into three categories: acute, cyclical, and chronic. Another used only the strongest-loaded item by dimension [30]. Finally, a total of nine studies deleted items or subscales [25,26,29,31,33,38-41]. Among them, three studies [38-40] removed the cause and identity subscales; two studies $[25,33]$ suppressed the identity or some items from this subscale [29]; and two others $[26,41]$ used only two subscales (timeline and personal control), and deleted all others.

\subsection{Brief Illness Perception Questionnaire (B-IPQ)}

The B-IPQ has also been used to assess illness representations in various mental disorders as shown in Table 2. Specifically, it was used for bipolar disorder $(n=7 ;[20,21,42-46])$, psychotic disorders $(n=4 ;[47-50])$, mixed mental disorders $(n=3 ;[51-53])$, attention deficit hyperactivity disorder $(n=2 ;[22,54])$, or unipolar disorders $(n=1 ;[55])$. As for IPQ-R, in order to adapt its use to mental disorders, the authors have made several adaptations and modifications, which are summarised in Table 3 . Among the modifications made, two studies replaced the term "illness" in the scale instructions with "mood swings" [42,43] or "attention deficit hyperactivity disorder" [22]. In addition, nine studies [20-22,42,43,45,46,52,53] changed the subscales of the B-IPQ. The cause subscale is the one that has been modified the most, either because it has been replaced by other tools (e.g. cause subscale of the IPQ-R [52,53], the perceived etiology of bipolar disorder $[45,46])$, because items have been added [52,53], or because open-ended questions were used $[22,42,43]$. Concerning other subscales, items have been added concerning personal effort $[42,43]$, self-blame $[42,43]$, or the degree of agreement with diagnosis $[20,21]$. Furthermore, one study used two items to measure treatment control instead of one [22]. Finally, a total of eight studies $[21,44,47-49,52,54,55]$ deleted items or subscales, especially cause $[21,44,47-49,54]$, coherence, concern $[52,55]$, treatment [52] and emotional representations [55]. 
Table 1

Description of the different tools used in mental health and the dimensions of the illness representations measured.

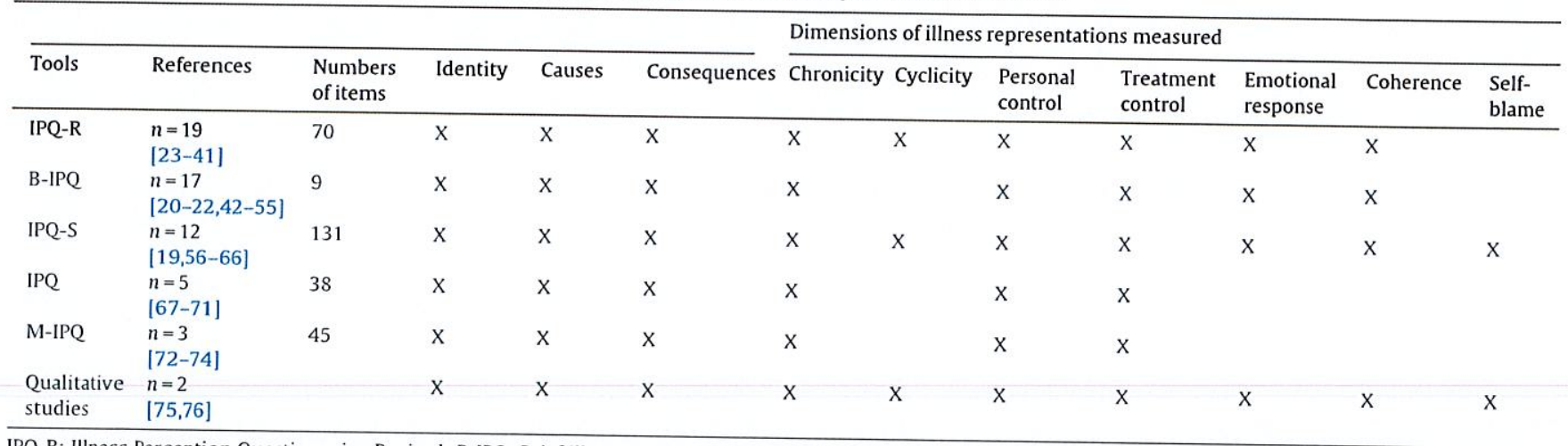

IPQ-R: Illness Perception Questionnaire-Revised; B-IPQ: Brief Illness Perception Questionnaire; IPQ-S: Illness Perception Questionnaire for schizophrenia; IPQ: Illness Perception Questionnaire. The number of items indicated here is that of the original versions of the tools. It does not take into account adaptations made in some studies. These
modifications are specified in Table 3.

Table 2

The tools used according to the disorder studied $(n)$.

\begin{tabular}{|c|c|c|c|c|c|c|}
\hline & IPQ-R & B-IPQ & IPQ-S & IPQ & M-IPQ & Qualitative method \\
\hline Psychotic disorders & - & 4 & 10 & 2 & 3 & 1 \\
\hline Unipolar disorders & 5 & 1 & - & 2 & - & 1 \\
\hline Bipolar disorders & 1 & 7 & 1 & - & - & - \\
\hline Mood disorders & 2 & - & - & - & - & - \\
\hline Eating disorders & 3 & - & - & - & - & - \\
\hline Mixed mental disorders & 7 & 3 & 1 & - & - & - \\
\hline PTSD & - & - & - & 1 & - & - \\
\hline ADHD & - & 2 & - & - & - & - \\
\hline Affective and disruptive disorders & 1 & - & - & - & - & - \\
\hline Total $n(\%)$ & 19 (33\%) & $17(29 \%)$ & $12(21 \%)$ & $5(9 \%)$ & $3(5 \%)$ & $2(3 \%)$ \\
\hline
\end{tabular}

IPQ-R: Illness Perception Questionnaire-Revised; B-IPQ: Brief Illness Perception Questionnaire; IPQ-S: Illness Perception Questionnaire for schizophrenia; IPQ: Illness Perception Questionnaire; ADHD: Attention deficit hyperactivity disorder; PTSD: Post-traumatic stress disorder.

Table 3

Mains modifications done according to the different tools $(n)$.

\begin{tabular}{llllll}
\hline & IPQ-R & B-IPQ & IPQ-S & IPQ \\
\hline Changes in terms & 7 & 3 & - & - \\
Changes in dimension(s)/item(s) & 7 & 9 & 2 & 4 \\
Deletions of dimension(s)/item(s) & 9 & 8 & 8 & 1 & 4 \\
\hline IPQ-R: Illness Perception Questionnaire-Revised: B-IPQ: Brief Illness Perception & - & 1 \\
\hline
\end{tabular}

Perception Questionnaire.

\subsection{Illness perception questionnaire for schizophrenia (IPQ-S)}

The IPQ-S was used primarily to explore illness perceptions of psychotic disorders $(n=10 ;[56-65])$ and more rarely for mixed disorders $(n=1 ;[66])$ and bipolar disorders $(n=1 ;[19])$. Although this scale has been validated specifically for schizophrenia, it has also undergone some changes, which are summarised in Table 3 . A total of eight studies $[19,56,57,59,61,63,64,66]$ removed subscales, including personal blame $[57,59,61,64,66]$, identity $[19,56,57,64]$, cause [56,57,59,61,63,64], cyclicity, personal control [57] and emotional representations [59]. In addition, two studies [58,62] modified the subscales, either by replacing the identity subscale with items from the positive and negative syndrome scale [58], or by categorising the cause subscale in three factors: mental health problems, side effects of medication, and other factors [62]. Finally, one study [61] used both the total score and the subscores of the IPQ-S. The IPQ-S is available in E-component (2).

\subsection{Illness perception questionnaire (IPQ)}

The IPQ was used to measure illness representations in psychotic disorders $(n=2 ;[67,68])$, unipolar disorders $(n=2 ;[69,70])$, and post-traumatic stress disorder $(n=1 ;[71])$. As with the IPQ$R$ and $B-I P Q$ several changes have been made by the authors to adapt these scales to psychiatric disorders. A total of four studies [68-71] changed the subscales of the IPQ. Among them, three studies changed the cause subscale, either by reducing it to two internal causes [68], or dividing it into five factors [69] or two factors [71]. In addition, two studies $[70,71]$ added items to assess perceived consequences; one study [69] added several items to assess emotional reactions; one other [71] reduced the controllability subscale; and one study [68] deleted the consequences and identity subscales.

\subsection{Modified illness perception questionnaire (M-IPQ)}

The M-IPQ has been used exclusively for psychotic disorders $(n=3 ;[72-74])$. Just like the IPQ-S, although this scale has been validated specifically for mental disorder, it has also undergone some changes, which are summarised in Table 3. Among the modifications made, one study [73] replaced the term "illness" in the scale instructions with "problems/illness". This same study added items to measure treatment and cure/control subscale. Finally, one study 
[74] added items to the cause subscale and reduced the items in the identity subscale to capture only positive symptoms.

\subsection{Illness representation/perception interview}

A qualitative method was used to explore illness perceptions in psychotic disorders (illness perception interview [76]) and in unipolar disorders (illness representations interview [75]). Among them, one study [76] asked participants to write on a paper "What do you understand by the term schizophrenia?". The second conducted an interview to assess the different dimensions of the illness representations [75].

\section{Discussion}

Across a wide range of mental disorders, illness perceptions are associated with health behaviour (e.g. adherence, preference for treatment) and psychosocial adjustment (e.g. quality of life) (for a review, see [12-14]). Thus, illness representations seem to provide an interesting heuristic framework for understanding the adaptation to illness of people with a mental disorder. However, illness representations have been studied mainly for physical diseases and much less for psychiatric disorders. In addition, most of the measurement tools have been validated exclusively with people with physical disorders. Consequently, the few studies conducted in the field of mental health have been confronted with the lack of tools specifically validated for mental disorders. Nevertheless, in order to have a reliable knowledge of illness representations for mental disorders, it is necessary to understand how these representations are captured. For these reasons, the objective of this study is to identify the tools and methods that have been used to evaluate the illness representations for people with mental disorders.

This mini review highlights that the main tools used to measure illness representations of psychiatric disorders are those initially created for physical diseases, such as IPQ-R and B-IPQ. However, in order to adapt their use to mental disorders, the authors have made several adaptations and modifications (e.g. subscales are modified or deleted, items are added). Even more surprisingly, even tools validated for mental disorders, such as the IPQ-S, are also widely modified in many studies. These multiple modifications and adaptations lead to questions about the reliability of what is measured. Indeed, the suppression of certain subscales is particularly problematic because illness representations are not necessarily independent [15]. In addition, measurement heterogeneity limits the replication of results and the emergence of reliable knowledge. On the basis of these different elements, we can interrogate whether we have a clear understanding of illness representations of mental disorders. To solve these problems, it is essential that we have a validated generic tool for mental disorders, like what is done in the somatic field with IPQ-R. To this end, the IPQ-S appears to be the most suitable. It has already been validated in English and German [58,60], used in bipolar disorders [19] and in various mental disorders [66]. Only the identity subscale of the IPQ-S, which measures perceived symptoms of schizophrenia, could be specific to the disorder being studied. Finally, the cause subscale is the one that has been most modified or deleted because it is judged to be either irrelevant or too difficult to analyse. Indeed, its analysis is very heterogeneous. Some studies examine each cause independently (e.g. [19]); others categorise causes into different factors (e.g. [33]). In concordance with Moss-Morris et al. [16], we recommend using the causal subscale of the IPQ-S and then performing a principal component analysis.

Beyond issues related to measurement tools, it is important to continue research on the illness representations in the field of psychiatry in order to better understand the processes underlying health behaviours of people with a mental disorder. To this end, reliable tools are needed. Therefore, in the future, it is essential that new tools be created and validated with people with mental disorders.

\section{Author contributions}

PA, EC and LD designed the study and drafted the manuscript.

\section{Disclosure of interest}

The authors declare that they have no competing interest.

\section{Acknowledgements}

This work was supported by "Fonds de dotation SolimutMutuelle de France".

\section{References}

[1] Fleury M-J, Grenier G, Bamvita J-M, et al. Predictors of quality of life in a longitudinal study of users with severe mental disorders. Health Qual Life Outcomes 2013;11:92.

[2] Alonso J, Angermeyer MC, Bernert S, et al. Disability and quality of life impact of mental disorders in Europe: results from the European Study of the Epidemiology of Mental Disorders (ESEMeD) project. Acta Psychiatr Scand Suppl 2004;109:38-46.

[3] Lacro JP, Dunn LB, Dolder CR, et al. Prevalence of and risk factors for medication nonadherence in patients with schizophrenia: a comprehensive review of recent literature. J Clin Psychiatry 2002;63:892-909.

[4] García S, Martínez-Cengotitabengoa M, López-Zurbano S, et al. Adherence to antipsychotic medication in bipolar disorder and schizophrenic patients. J Clin Psychopharmacol 2016;36:355-71.

[5] Ho SC, Chong HY, Chaiyakunapruk N, et al. Clinical and economic impact of non-adherence to antidepressants in major depressive disorder: a systematic review. J Affect Disord 2016;193:1-10.

[6] Rosenstock IM. Why people use health services. Millbank Meml Fund Q 1966;44:94-127.

[7] Leventhal H, Nerenz D, Steel D, et al. Illness representations and coping with health threats. In: Baum A, Singer J, editors. A handbook of psychology and health, 1. Hillsdale, New Jersey, NJ: Lawrence Erlbaum Associates; 1984. p. 221-52.

[8] Ajzen I. The theory of planned behaviour organisational behaviour and human decision processes. Organ Behav Hum Decis Process 1991;50:179-211.

[9] Michie S, van Stralen MM, West R. The behaviour change wheel: a new method for characterising and designing behaviour change interventions. Implement Sci 2011;6:42.

[10] Hagger MS, Orbell S. A meta-analytic review of the common-sense model of illness representations. Psychol Heal 2003;18:141-84.

[11] Hagger MS, Koch S, Chatzisarantis NLD, et al. The common sense model of self-regulation: meta-analysis and test of a process model. Psychol Bull 2017; 143:1117-54.

[12] Baines T, Wittkowski A. A systematic review of the literature exploring illness perceptions in mental health utilising the self-regulation model. J Clin Psychol Med Settings 2013;20:263-74.

[13] Lobban F, Barrowclough C, Jones S. A review of the role of illness models in sever mental illness. Clin Psychol Rev 2003;23:171-96.

[14] Averous P, Charbonnier E, Dany L. Relationship between illness representations, psychosocial adjustment, and treatment outcomes in mental disorders: a mini
review. Front Psychol 2020;11:1167.

[15] Weinman J, Petrie KJ, Moss-morris R, et al. The illness perception questionnaire: a new method for assessing the cognitive representation of illness. Psychol Health 1996;11:431-45.

[16] Moss-Morris R, Weinman J, Petrie KJ, et al. The revised illness perception questionnaire (IPQ-R). Psychol Heal 2002;17:1-16.

[17] Broadbent E, Petrie KJ, Main J, et al. The brief illness perception questionnaire. J Psychosom Res 2006;60:631-7. [18] Kaptein AA. Brief IPQ: some remarks on a success story. Psychol Heal
2016:31:379-82.

[19] Averous P, Charbonnier E, Lagouanelle-Simeoni MC, et al. Illness perceptions and adherence in bipolar disorder: an exploratory study. Compr Psychiatry 
[20] Etain B, Scott J, Cochet B, et al. A study of the real-world effectiveness of group psychoeducation for bipolar disorders: is change in illness perception a key mediator of benefit? J Affect Disord 2018;227:713-20.

[21] M'Bailara K, Minois I, Zanouy L, et al. Therapeutic education: a lever to change perceptions of bipolar disorder in family caregivers. Encéphale 2019:45:239-44

[22] Wong IYT, Hawes DJ, Dar-Nimrod I. Illness representations among adolescents with attention deficit hyperactivity disorder: associations with quality of life, coping, and treatment adherence. Heliyon 2019;5:e02705.

[23] Franz M, Salize HJ, Lujic C, et al. Illness perceptions and personality traits of patients with mental disorders: the impact of ethnicity. Acta Psychiatr Scand 2014:129:143-55.

[24] Hunot VM, Horne R, Leese MN, et al. A cohort study of adherence to antidepressants in primary care: the influence of antidepressant concerns and treatment preferences. Prim Care Companion J Clin Psychiatry 2007;9:91-9.

[25] Imran N, Azeem MW, Chaudhry MR, et al. Illness perceptions in adolescents with a psychiatric diagnosis in Pakistan. BJPsych Bull 2015;39:174-8

[26] Moses T. What helps or undermines adolescents' anticipated capacity to cope with mental illness stigma following psychiatric hospitalisation. Int J Soc Psychiatry 2015;61:215-24.

[27] Vanheusden K, van der Ende J, Mulder CL, et al. Beliefs about mental health problems and help-seeking behaviour in Dutch young adults. Soc Psychiatry Psychiatr Epidemiol 2009;44:239-46.

[28] Ward EC, Heidrich SM. African-American women's beliefs about mental illness, stigma, and preferred coping behaviours. Res Nurs Heal 2009;32:480-92.

[29] Witteman C, Bolks L, Hutschemaekers G. Development of the illness perception questionnaire mental health. J Ment Heal 2011;20:115-25.

[30] Aikens JE, Nease DE, Klinkman MS. Explaining patients' beliefs about the necessity and harmfulness of antidepressants. Ann Fam Med 2008;6:23-9.

[31] Cabassa LJ, Lagomasino IT, Dwight-Johnson M, et al. Measuring latinos' perceptions of depression: a confirmatory factor analysis of the illness perception questionnaire. Cult Divers Ethn Minor Psychol 2008;14:377-84.

[32] Elwy RA, Glickman ME, Bokhour BG, et al. Using mixed methods to examine the role of veterans' illness perceptions on depression treatment utilisation and HEDIS concordance. Med Care 2016;54:e35-42.

[33] Houle J, Villaggi B, Beaulieu MD, et al. Treatment preferences in patients with first-episode depression. J Affect Disord 2013;147:94-100.

[34] Lu Y, Tang C, Liow CS, et al. A regressional analysis of maladaptive rumination, illness perception and negative emotional outcomes in Asian patients suffering from depressive disorder. Asian J Psychiatr 2014;12:69-76.

[35] DeJong H, Hillcoat J, Perkins S, et al. Illness perception in bulimia nervosa. J Health Psychol 2012;17:399-408.

[36] Holliday J, Wall E, Treasure J, et al. Perceptions of illness in individuals with anorexia nervosa: a comparison with lay men and women. Int J Eat Disord 2005;37:50-6.

[37] Quiles Marcos Y,Weinman J, Terol Cantero MC, et al. The dissimilarity between patients' and relatives' perception of eating disorders and its relation to patient adjustment. J Health Psychol 2009;14:306-12.

[38] Munson MR, Floersch JE, Townsend L. Attitudes toward mental health services and illness perceptions among adolescents with mood disorders. Child Adolesc Soc Work J 2009;26:447-66.

[39] Munson MR, Floersch JE, Townsend L. Are health beliefs related to adherence among adolescents with mood disorders? Adm Policy Ment Health 2010:37:408-16.

[40] Hou R, Cleak V, Peveler R. Do treatment and illness beliefs influence adherence to medication in patients with bipolar affective disorder? A preliminary crosssectional study. Eur Psychiatry 2010;25:216-9

[41] Moses T. Being treated differently: stigma experiences with family, peers, and school staff among adolescents with mental health disorders. Soc Sci Med 2010;70:985-93.

[42] Dodd AL, Mezes B, Lobban F, et al. Psychological mechanisms and the ups and downs of personal recovery in bipolar disorder. Br J Clin Psychol 2017;56:310-28.

[43] Lobban F, Solis-Trapala I, Tyler E, et al. The role of beliefs about mood swings in determining outcome in bipolar disorder. Cognit Ther Res 2013:37:51-60.

[44] Oflaz S, Guveli H, Kalelioglu T, et al. Illness perception of dropout patients followed up at bipolar outpatient clinic, Turkey. Asian J Psychiatr 2015;15:68-72.

[45] Peay HL, Rosenstein DL, Biesecker BB. Adaptation to bipolar disorder and perceived risk to children: a survey of parents with bipolar disorder. BMC Psychiatry 2013;13:327.

[46] Peay HL, Rosenstein DL, Biesecker BB. Parenting with bipolar disorder: coping with risk of mood disorders to children. Soc Sci Med 2014;104:194-200.

[47] Gómez-de-Regil L, Kwapil TR, Barrantes-Vidal N. Illness perception mediates the effect of illness course on the quality of life of Mexican patients with psychosis. Appl Res Qual Life 2014;9:99-112.

[48] Maguire PA, Reay RE, Raphael B. Correlates of a single-item self-rated mental health question in people with schizophrenia. Australas Psychiatry 2016;24:473-7.

[49] Moriarty A, Jolley S, Callanan MM, et al. Understanding reduced activity in psychosis: the roles of stigma and illness appraisals. Soc Psychiatry Psychiatr Epidemiol 2012;47:1685-93.
[50] Sanders D, Kydd R, Morunga E, et al. Differences in patients' perceptions of schizophrenia between Măori and New Zealand Europeans. Aust New Zeal J Psychiatry 2011;45:483-8.

[51] Broadbent E, Kydd R, Sanders D, et al. Unmet needs and treatment seeking in high users of mental health services: role of illness perceptions. Aust N Z J Psychiatry 2008;42:147-53.

[52] Chan RCH, Mak WWS. Common sense model of mental illness: understanding the impact of cognitive and emotional representations of mental illness on recovery through the mediation of self-stigma. Psychiatry Res 2016;246:16-24.

[53] Reich H, Bockel L, Mewes R. Motivation for psychotherapy and illness beliefs in Turkish immigrant inpatients in Germany: results of a cultural comparison study. J Racial Ethn Heal Disparities 2015;2:112-23.

[54] Emilsson M, Gustafsson PA, Öhnström G, et al. Beliefs regarding medication and side effects influence treatment adherence in adolescents with attention deficit hyperactivity disorder. Eur Child Adolesc Psychiatry 2017;26:559-71.

[55] Lynch J, Moore M, Moss-Morris R, et al. Are patient beliefs important in determining adherence to treatment and outcome for depression? Development of the beliefs about depression questionnaire. J Affect Disord 2011;133:29-41.

[56] Beck E-M, Vögelin R, Wirtz M, et al. Do patients with schizophrenia distinguish between attitudes toward antipsychotic medication and pharmacotherapy in general? J Nerv Ment Dis 2012;200:33-43.

[57] Cavelti M, Beck EM, Kvrgic S, et al. The role of subjective illness beliefs and attitude toward recovery within the relationship of insight and depressive symptoms among people with schizophrenia spectrum disorders. J Clin Psychol 2012;68:462-76

[58] Cavelti M, Contin G, Beck EM, et al. Validation of the illness perception questionnaire for schizophrenia in a German speaking sample of outpatients with chronic schizophrenia. Psychopathology 2012;45:259-69.

[59] Lobban F, Barrowclough C, Jones S. The impact of beliefs about mental health problems and coping on outcome in schizophrenia. Psychol Med 2004;34:1165-76.

[60] Lobban F, Barrowclough C, Jones S. Assessing cognitive representations of mental health problems. I. The illness perception questionnaire for schizophrenia. Br J Clin Psychol 2005;44:147-62.

[61] Lobban F, Barrowclough C, Jones S. Does expressed emotion need to be understood within a more systemic framework? An examination of discrepancies in appraisals between patients diagnosed with schizophrenia and their relatives. Soc Psychiatry Psychiatr Epidemiol 2006;41:50-5.

[62] Rungruangsiripan M, Sitthimongkol Y, Maneesriwongul W, et al. Mediating role of illness representation among social support, therapeutic alliance, experience of medication side effects, and medication adherence in persons with schizophrenia. Arch Psychiatr Nurs 2011;25:269-83.

[63] Stainsby M, Sapochnik M, Bledin K, et al. Are attitudes and beliefs about symptoms more important than symptom severity in recovery from psychosis? Psychosis 2010;2:41-9.

[64] Theodore K, Johnson S, Chalmers-Brown A, et al. Quality of life and illness beliefs in individuals with early psychosis. Soc Psychiatry Psychiatr Epidemiol 2012;47:545-51.

[65] Wall ELE, Mirfin D, White S, et al. Patient perceptions of schizophrenia in forensic and general adult psychiatry. J Forensic Psychiatry Psychol 2017;28:357-67.

[66] Williams K, Steer H. Illness perceptions: are beliefs about mental health problems associated with self-perceptions of engagement in people with psychosis? Behav Cogn Psychother 2011;39:151-63.

[67] Fialko L, Freeman D, Bebbington PE, et al. Understanding suicidal ideation in psychosis: findings from the psychological prevention of relapse in psychosis (PRP) trial. Acta Psychiatr Scand 2006;114:177-86

[68] Iyassu R, Jolley S, Bebbington P, et al. Psychological characteristics of religious delusions. Soc Psychiatry Psychiatr Epidemiol 2014;49:1051-61.

[69] Kelly MAR, Sereika SM, Battista DR, et al. The relationship between beliefs about depression and coping strategies: gender differences. Br J Clin Psychol 2007; $46: 315-32$

[70] O'Mahen HA, Flynn HA, Chermack S, et al. Illness perceptions associated with perinatal depression treatment use. Arch Womens Ment Health 2009;12:447-50.

[71] Spoont M, Sayer N, Nelson DB. PTSD and treatment adherence: the role of health beliefs. J Nerv Ment Dis 2005;193:515-22.

[72] Freeman D, Dunn G, Garety P, et al. Patients' beliefs about the causes, persistence and control of psychotic experiences predict take-up of effective cognitive behaviour therapy for psychosis. Psychol Med 2013;43:269-77.

[73] Marcus E, Garety P, Weinman J, et al. A pilot validation of a modified illness perceptions questionnaire designed to predict response to cognitive therapy for psychosis. J Behav Ther Exp Psychiatry 2014;45:459-66.

[74] Watson PWB, Garety Pa, Weinman J, et al. Emotional dysfunction in schizophrenia spectrum psychosis: the role of illness perceptions. Psychol Med 2006;36:761-70

[75] Karasz A, García N, Ferri L, et al. Conceptual models of depression in primary care patients: a comparative study. J Cross Cult Psychol 2009;40:1041-59.

[76] Lobban F, Barrowclough C. Common sense representations of schizophrenia in patients and their relatives. Clin Psychol Psychother 2005;12:134-41. 